\title{
Climate Sensitive Urban Design pada Kawasan Pecinan Kota Semarang
}

\author{
Climate Sensitive Urban Design in the Chinatown of Semarang City
}

\author{
Rina Kurniati ${ }^{1}$, Wakhidah Kurniawati ${ }^{1}$ and Diah Intan Kusumo Dewi ${ }^{1}$, dan Talitha Zuleika \\ Islamey ${ }^{1}$
}

Diterima: 19 Agustus 2020

Disetujui: 15 September 2020

\begin{abstract}
Kawasan Pecinan merupakan kawasan bersejarah yang memiliki kepadatan bangunan yang tinggi dan memiliki pola kawasan berbentuk grid karena fungsinya sebagai perdagangan dan jasa. Beragamnya peruntukan fungsi kawasan sehingga tingginya aktivitas yang dilakukan diluar ruangan terutama pada akhir pekan. Penelitian ini bertujuan untuk memberikan arahan pengelolaan lingkungan Kawasan Pecinan Kota Semarang sebagai upaya dalam mitigasi bencana perubahan iklim dengan konsep Climate Sensitive Urban Design. Data didapatkan dengan observasi ke lapangan kemudian diidentifikasi koefisien dasar bangunan (KDB) dan koefisien lantai bangunan (KLB). Pengukuran suhu udara, kecepatan angin dan kelembaban dilakukan pada waktu pagi, siang dan sore hari. Data yang diperoleh kemudian disimulasikan menggunakan ArcGis 10.3 guna menguji tingkat kenyamanan termal. Berdasarkan simulasi Kawasan Pecinan tergolong Tidak nyaman dengan tingkat lebih besar dari angka $27^{\circ} \mathrm{C}$. Iklim mikro Kawasan Pecinan dipengaruhi oleh tutupan lahan, bangunan serta frekuensi lalu lintas atau aktivitas lingkungan. Sehingga konsep climate sensitive urban design yang sesuai untuk diterapkan pada Kawasan Pecinan adalah optimalisasi pengadaan tanaman dalam pot, tanaman gantung pada kanopi bangunan, vegetasi merambat pada dinding bangunan dan optimalisasi penggunan moda angkutan umum menuju kawasan.
\end{abstract}

Keyword: kenyamanan thermal, pecinan, desain

\begin{abstract}
The Chinatown area is a historic area that has a high building density and has a grid-shaped pattern due to its function as trade and services. The various designations of the area function so that the high activity is carried out outside the room, especially on weekends. This study aims to provide direction for environmental management in the Chinatown area of Semarang City as an effort to mitigate climate change disasters with the concept of Climate Sensitive Urban Design. Data obtained by field observations then identified the Building Coverage Ratio (BCR) and floor area Ratio (FAR). Measurement of air temperature, wind speed and humidity is carried out in the morning, afternoon and evening. Simulated data using ArcGis 10.3 to test the thermal comfort. Based on that, the Chinatown is classified as Uncomfortable area more than $27^{\circ} \mathrm{C}$. The microclimate of the Chinatown area is influenced by landuse, building, and the frequency of traffic. So the concept of the climate sensitive urban design is suitable for the Chinatown area with optimization of the potted plants, hanging plants on the canopy, vine vegetation on walls and use public transportation modes to the area.
\end{abstract}

Keywords: thermal comfort, Chinatown, design

\footnotetext{
${ }^{1}$ Departmen Perencanaan Wilayah dan Kota, Fakultas Teknik,Universitas Diponegoro
} 


\section{PENDAHULUAN}

Tingginya aktifitas manusia pada kawasan perkotaan menyebabkan suhu kawasan perkotaan lebih tinggi dibandingkan kawasan pinggirannya. Fenomena ini disebut Urban Heat Island (UHI) yaitu sebuah fenomena perbedaan suhu di kawasan perkotaan yang menjadi lebih tinggi dibandingkan kawasan sekitarnya karena tingginya ruang terbangun(Giannopoulou et al., 2011; Kolokotroni \& Giridharan, 2008). Kondisi iklim atau suhu kawasan berpengaruh pada kenyamanan seseorang untuk beraktifitas. Fisik bangunan juga berpengaruh terhadap kenyamanan (Wismonowati, 2012). Dalam perdebatan mengenai bagaimana pentingnya suatu kota dalam menciptakan kehidupan kota yang nyaman dan aman bagi masyarakatnya, suhu permukaan kota menjadi salah satu indikator yang berperan penting dalam membentuk kota layak huni (Djukic, Vukmirovic, \& Stankovic, 2016).

Kota Semarang mengalami peningkatan lahan terbangun dalam kurun waktu 10 tahun hingga mencapai angka 13\%(Pamungkas, Munibah, \& Soma, 2019). Peralihan ini terjadi paling banyak pada fungsi lahan pertanian. Perubahan guna lahan dipengaruhi oleh pertumbuhan penduduk yang meningkat sehingga memicu semakin panasnya suhu permukaan di Kota Semarang akibat tingginya aktifitas yang terjadi pada kawasan perkotaan. Berdasarkan data iklim, terjadi perubahan suhu di Kota Semarang menjadi 22$40{ }^{\circ} \mathrm{C}$ pada tahun 2018 yang pada tahun 2008 suhu permukaan rata-ratanya hanya sebesar $18-33^{\circ} \mathrm{C}$.

Upaya mitigasi yang dapat dilakukan yaitu redesign kawasan. Perlu adanya penyesuaian elemen desain perancangan kota yang dapat menyesuaikan dengan kondisi temperature kota yang semakin panas( Djukic et al., 2016). Dalam konteks rancang kota perencanaan kawasan yang tanggap iklim dapat dilakukan dengan penerapan konsep climate sensitive urban design. Climate sensitive Urban Design (CSUD) merupakan salah satu konsep dalam perencanaan dan perancangan kawasan yang tanggap terhadap unsur iklim serta menjadi pendekatan yang mengacu terhadap isu sustainable development (Emmanuel, 2005). Kriteria yang digunakan dalam Climate sensitive Urban Design merupakan karakteristik iklim mikro diantaranya pencahayaan matahari, kecepatan angin dan temperature dengan skala perkotaan(Kaya \& Mengi, 2011; Tapias \& Schmitt, 2014). Sehingga konsep ini dapat menjadi penyelesaian permasalahan dalam konteks rancang kota. Selain itu konsep ini merupakan dasar untuk mencapai tingkat kenyamanan termal terhadap pengguna ruang pada kawasan perkotaan.

Tingkat kenyamanan termal pada suatu kawasan merupakan salah satu komponen penting dalam perencanaan dan perancangan desain perkotaan. Tolak ukur kenyamanan termal didasarkan melalui faktor elemen iklim mikro diantaranya yang dapat mempengaruhi kondisi kawasan (Koch-Nielsen, 2002). Tingkat kenyamanan termal berpengaruh terhadap aktivitas yang terjadi di luar ruang maupun dalam ruang. Luar ruang merupakan suatu wadah aktivitas pada dasarnya harus memiliki tingkat kenyaman alami sehingga menciptakan kenyamanan bagi pengguna di dalamnya. Evaluasi kenyamanan termal perlu dilakukan guna menjadi panduan dalam perancangan kota sebagai upaya peningkatan kualitas hidup masyarakat perkotaan (Koerniawan, 2015). Pengguna ruang dapat merasakan tingkat kenyamanan termal pada skala tertentu, menurut Laurie, (1990) kondisi nyaman apabila nilai standar Temperature Humadity Index (THI) antara $21-27$, serta memiliki suhu ideal yang dapat di terima manusia yaitu antara $27^{\circ} \mathrm{C}-28^{\circ} \mathrm{C}$ dengan nilai kelembaban $40 \%$.

Seiring perkembangan Kota Semarang menuju era modernisasi hingga sekarang, perkampungan masyarakat Tionghoa di Kawasan Pecinan semakin tumbuh apabila dilihat dari lokasinya yang berdekatan dengan pusat perdagangan. Hingga saat ini Kawasan Pecinan memiliki fungsi campuran. Berdasarkan peraturan Daerah Kota Semarang No 14 Tahun 2011 terkait Rencana Tata Ruang Wilayah Kota Semarang Tahun 2011 - 2031 Kawasan Pecinan termasuk kedalam BWK I yaitu sebagai kawasan perkantoran, perdagangan dan jasa (Pemerintah Kota Semarang, 2011). Selain itu berdasarkan Surat 
Keputusan (SK) Wali Kota No 650/157 tanggal 28 Juni 2005 yang mengatur dan menetapkan Kawasan Pecinan sebagai kawasan revitalisasi dan pusat wisata budaya Kota Semarang (Widiastuti, 2015).

Tingginya aktivitas yang terjadi pada Kawasan Pecinan ditunjukan dengan tingginya mobilitas kendaraan yang keluar masuk kawasan, kepadatan bangunan dan langgam bangunan hunian yang didominasinya oleh bangunan rumah toko. Hal tersebut menyebabkan suhu Kawasan Pecinan terasa lebih tinggi dibandingkan kawasan disekitarnya. Terutama pada siang hari, tutupan lahan yang hanya berupa aspal dan beton semakin menambah tingkat suhu permukaan. Oleh karena itu perlu dilakukan redesign kawasan, guna memberikan kenyamanan untuk aktivitas luar ruangan pada Kawasan Pecinan Semarang. Konsep Climate Sensitive Urban Design menjadi solusi rancang kota untuk diterapkan pada Kawasan Pecinan Kota Semarang. Melalui pengkajian karakteristik iklim mikro, nantinya akan diperoleh tingkat kenyamanan thermal kawasan terhadap pengguna kawasan sehingga dapat mendukung pembangunan yang berkelanjutan di kota Semarang.

\section{METODE}

Pengumpulan data dilakukan dengan survey langsung di lapangan melalui pengukuran terhadap iklim mikro (pencahayaan matahari, kecepatan angin, temperature udara) dan kenyamanan thermal ruang luar (temperatur udara, kecepatan angin dan kelembaban kawasan). Data lapangan dianalisis menggunakan software arcgis 10.3 dengan metode IDW (Inverse Distance Weighted) yaitu metode interpolasi permukaan dengan asumsi jarak sebagai bobot, semakin dekat data sampel maka nilai interpolasinya semakin akurat (Pramono, 2008). Hasil yang diperoleh berupa peta digital yang berisi data grafis dan atributnya. Kemudian untuk kenyamanan thermal luar ruang diperoleh dengan perhitungan suhu dan kelembaban pada masing-masing station. Menggunakan persamaan Mc Gregor dan Nieuwolt (1975) dalam Rachma, (2018):

\section{Keterangan :}

$$
T H I=0,8 \times \operatorname{Tr}+\left(\frac{R H \times T r}{500}\right)
$$

THI : Temperature Humidity Index

$\operatorname{Tr} \quad$ : Suhu Udara $\left({ }^{\circ} \mathrm{C}\right)$

RH : Kelembaban Relatif

Hasil perhitungan yang diperoleh kemudian dilakukan permodelan iklim mikro terhadap urban design menggunakan metode korelasional dan simulasi. Metode korelasi yang digunakan berupa metode regresi linier berganda dengan bantuan aplikasi SPSS Statistic 24 . Sebelum memasuki aplikasi SPSS data yang bentuknya berbeda disetarakan terlebih dahulu dengan proses pengkodean. Proses korelasi yang dilakukan untuk mengetahui pengaruh elemen urban design seperti material, bayangan, orientasi, geometri $(\mathrm{H} / \mathrm{W})$, frekuensi lalu lintas, dan keberadaan vegetasi dapat mempengaruhi kondisi iklim mikro untuk kemudian dapat menjadi rekomendasi dalam penentuan konsep penyesuaian. Metode simulasi yang dilakukan dalam penelitian ini mencakup simulasi kenyamanan termal dan pembayangan dengan bantuan aplikasi seperti ArcGIS 10.3, Ecotect Analysis 2011, dan Sketchup 2016. Dimana proses pemodelan iklim terhadap urban design menggunakan cara interpolasi data spasial. Data dalam bentuk 2 dimensi kemudian diinput ke dalam aplikasi Sketchup 2016 untuk dilakukan permodelan 3 dimensi dan permodelan bayangan dengan menggunakan koordinat dari analisis spasial ArcGIS 10.3. Aplikasi Ecotect Analysis 2011 digunakan untuk pemodelan arah matahari dan juga persentase pembayangan yang dihasilkan pada kawasan. 


\section{Pengukuran dan Perhitungan Iklim Mikro}

Pengukuran Iklim mikro dihitung menggunakan metode Temperature Humidity Index (THI) agar nantinya diperoleh nilai tingkat kenyamanan thermal kawasan. Pengukuran di dasarkan pada rata - rata suhu udara dan kelembaban relatif. Pada penelitian ini pengukuran dilakukan pukul 09.30 WIB, 12.30 WIB, 16.00 WIB pada Kawasan Pecinan Semarang. Selain itu agar mendapat tingkat kenyamanan yang sesuai maka titik station atau titik ukur akan disebar secara acak pada lokasi jalan gang gambiran (station 1), jalan gang warung (station 2), dan jalan gang pinggirin (station 3).

\section{Suhu Udara}

Hasil interpolasi IDW pada pukul 09.30 WIB, di peroleh hasil station 1 memiliki rata - rata suhu $32^{\circ} \mathrm{C}-33,4^{\circ} \mathrm{C}$ lebih rendah dibandingkan dengan station 2 dengan rata - rata suhu $34,8^{\circ} \mathrm{C}-36,2^{\circ} \mathrm{C}$ dan station 3 memiliki rata - rata suhu tertinggi dibandingkan kawasan lainnya mencapai $37,6^{\circ} \mathrm{C}-38,8^{\circ} \mathrm{C}$. kawasan di luar station pengukuran memiliki rata - rata suhu $33,4^{\circ} \mathrm{C}-34,7^{\circ} \mathrm{C}$ dan $36,2^{\circ} \mathrm{C}-37,6^{\circ} \mathrm{C}$. Pada siang hari pukul $12.30 \mathrm{WIB}$, hasil interpolasi yang diperoleh pada station 1 memiliki rata - rata suhu $38^{\circ} \mathrm{C}-38,2^{\circ} \mathrm{C}$ lebih rendah dibandingkan dengan station 2 dan station 3. Nilai rata - rata suhu pada 2 station tersebut lebih tinggi di bandingkan kawasan lainnya mencapai $38,8^{\circ} \mathrm{C}-39^{\circ} \mathrm{C}$, sedangkan kawasan di luar station pengukuran memiliki rata - rata suhu $38,2^{\circ} \mathrm{C}-38,4^{\circ} \mathrm{C}, 38,4^{\circ} \mathrm{C}-$ $38,6^{\circ} \mathrm{C}$ dan $38,6^{\circ} \mathrm{C}-38,8^{\circ} \mathrm{C}$. Sementara itu, hasil interpolasi pada sore hari atau sekitar pukul 16.00 WIB, station 1 dan station 3 memiliki rata - rata suhu $34^{\circ} \mathrm{C}-34,2^{\circ} \mathrm{C}$ lebih rendah dibandingkan dengan station 2 . Rata - rata suhu station 2 merupakan yang tertinggi dibandingkan kawasan lainnya yaitu $34,8^{\circ} \mathrm{C}-35^{\circ} \mathrm{C}$, sedangkan kawasan di luar station pengukuran memiliki rata - rata suhu $34,2^{\circ} \mathrm{C}-34,4^{\circ} \mathrm{C}, 34,4^{\circ} \mathrm{C}-34,6^{\circ} \mathrm{C}$ dan $34,6^{\circ} \mathrm{C}-$ $34,8^{\circ} \mathrm{C}$.

\section{Tingkat Kelembaban}

Persentase kelembaban tiga station cenderung memiliki persentase yang sama yaitu $66 \%$ pada pukul 09.30 WIB. Pukul $12.30 \mathrm{WIB}$, setiap station mengalami penurunan kelembaban menjadi $62 \%$. Sementara itu, pada pukul 16.00 WIB station 1 mengalami penurunan tingkat kelembaban mencapai $43 \%$ sedangkan pada station 2 dan 3 mengalami penurunan tingkat kelembaban lebih rendah mencapai $41 \%$. Berdasarkan persentase kelembaban pada masing - masing station, tingkat kelembaban dapat dikatakan normal karena berada diantara standar interval 20\% - 90\%, persentase kelembaban ini dipengaruhi oleh tinggi rendahnya suhu pada masing - masing station.

\section{Perhitungan Kenyamanan Termal}

Kenyamanan termal diukur menggunakan persamaan 1 dengan meinputkan nilai iklim mikro yang telah diperoleh sebelumnya, hasilnya diperoleh bahwa tingkat kenyamanan pada setiap station masuk ke dalam kategori tidak nyaman. Hal tersebut dikarenakan rata - rata suhu pada Kawasan Pecinan tertinggi $38,9^{\circ} \mathrm{C}$ dan terendah $32,7^{\circ} \mathrm{C}$ sedangkan nilai Temperature Humidity Index (THI) tertinggi mencapai 34,1 dan nilai terendah mencapai 33,0. Menurut Laurie (2009) suhu udara ideal untuk kenyamanan manusia sebagai pengguna ruang luar antara $27^{\circ} \mathrm{C}-28^{\circ} \mathrm{C}$, sedangkan nilai kenyamanan berkisar antara $21^{\circ} \mathrm{C}-27^{\circ} \mathrm{C}$.

Tabel 1 Kenyamanan Termal Kawasan Pecinan

\begin{tabular}{cccccccc}
\hline Lokasi & Waktu & $\mathbf{T}^{\circ} \mathbf{C}$ & $\begin{array}{c}\text { Kelembaban } \\
\%\end{array}$ & $\begin{array}{c}\text { Rata }- \\
\text { rata } \mathbf{T r} \\
{ }^{\circ} \mathbf{C}\end{array}$ & $\begin{array}{c}\text { Rata- } \\
\text { Rata HR } \\
\mathbf{\%}\end{array}$ & $\begin{array}{c}\text { Nilai } \\
\mathbf{T H I}^{\circ} \mathbf{C}\end{array}$ & Kategori \\
\hline \multirow{2}{*}{ Station 1 } & $09.30 \mathrm{WIB}$ & 32,7 & 66 & & & & Tidak \\
& $12.30 \mathrm{WIB}$ & 38,1 & 62 & 34,4 & 57 & 31,4 & Nyaman \\
\hline
\end{tabular}




\begin{tabular}{cccccccc}
\hline Lokasi & Waktu & $\mathbf{T}^{\circ} \mathbf{C}$ & $\begin{array}{c}\text { Kelembaban } \\
\%\end{array}$ & $\begin{array}{c}\text { Rata- } \\
\text { rata } \mathbf{T r} \\
{ }^{\circ} \mathbf{C}\end{array}$ & $\begin{array}{c}\text { Rata- } \\
\text { Rata HR } \\
\%\end{array}$ & $\begin{array}{c}\text { Nilai } \\
\mathbf{T H I}{ }^{\circ} \mathbf{C}\end{array}$ & Kategori \\
\hline \multirow{2}{*}{ Station 2 } & $09.30 \mathrm{WIB}$ & 35,5 & 66 & & & & Tidak \\
& $12.30 \mathrm{WIB}$ & 38,9 & 62 & 36,2 & 56,3 & 33,0 & Nyaman \\
& $16.00 \mathrm{WIB}$ & 34,9 & 41 & & & & \\
Station 3 & $09.30 \mathrm{WIB}$ & 38,3 & 66 & & & & Tidak \\
& $12.30 \mathrm{WIB}$ & 38,9 & 62 & 37,4 & 56,3 & 34,1 & Nyaman \\
\hline
\end{tabular}

\section{Pengaruh Angin terhadap Kenyamanan Termal}

Kecepatan angin pada masing - masing station memiliki nilai yang tinggi dibandingkan dengan standar kecepatan angin yaitu $0,15-0,25 \mathrm{~m} / \mathrm{s}$, namun berdasarkan klasifikasi skala beufort kecepatan angin pada station 1 dan station 2 dikategorikan Light Airs, sedangkan pada station 3 dikategorikan Light Breeze. Pada pukul 12.30 WIB hingga 16.00 WIB pada masing - masing station dikategorikan Light Breeze. Berdasarkan presepsi pengguna ruang luar kecapetan angin pada masing - masing station masih dianggap tidak mengganggu aktivitas, karena pada dasarnya arah dan kecepatan angin dapat membantu vegetasi mendinginkan suhu, sehingga menciptakan kenyamanan bagi pengguna ruang.

Tabel 2 Kecepatan Angin Kawasan Pecinan

\begin{tabular}{clcl}
\hline Time & Location & $\begin{array}{c}\text { Wind Speed } \\
(\mathbf{m} / \mathbf{s})\end{array}$ & Description \\
\hline \multirow{3}{*}{09.30 WIB } & Station 1 & $1 \mathrm{~m} / \mathrm{s}$ & Light Airs \\
& Station 2 & $1 \mathrm{~m} / \mathrm{s}$ & Light Airs \\
& Station 3 & $3 \mathrm{~m} / \mathrm{s}$ & Light Breeze \\
& Station 1 & $2 \mathrm{~m} / \mathrm{s}$ & Light Breeze \\
\multirow{2}{*}{12.30 WIB } & Station 2 & $2 \mathrm{~m} / \mathrm{s}$ & Light Breeze \\
& Station 3 & $4 \mathrm{~m} / \mathrm{s}$ & Light Breeze \\
& Station 1 & $4 \mathrm{~m} / \mathrm{s}$ & Light Breeze \\
& Station 2 & $2 \mathrm{~m} / \mathrm{s}$ & Light Breeze \\
& Station 3 & $2 \mathrm{~m} / \mathrm{s}$ & Light Breeze \\
\hline
\end{tabular}

\section{Pengaruh Vegetasi Terhadap Kenyamanan Termal}

Vegetasi mampu membantu dalam proses pendinginan suhu udara mencapai $2^{\circ} \mathrm{C}-$ $3 \mathrm{C}^{\circ}$. Pada masing - masing station tidak banyak di temukan vegetesi karena kawasan tersebut didominasi kawasan terbangun diantaranya pertokoan dan permukiman, sehingga suhu udara pada Kawasan Pecinan cenderung tinggi.

\section{Hubungan Iklim Mikro dan Urban Design Kawasan Pecinan}

Iklim mikro pada Kawasan Pecinan lebih dipengaruhi oleh material tutupan lahan dan bangunan serta frekuensi lalu lintas atau aktivitas lingkungan. Penelitian sebelumnya yang dilakukan oleh Nichol, Fung, Lam, \& Wong (2009) antara suhu permukaan tanah dan suhu udara terhadap perubahan dan jenis tutupan lahan (material termal) menunjukan hubungan yang signifikan. Kawasan Pecinan didominasi oleh penggunaan lahan sebagai bangunan dua lantai dengan kepadatan tinggi dengan mayoritas penggunaan material paving dan beton yang merupakan material yang memantulkan panas lebih baik dibandingkan material alami. Selain itu, sebagai kawasan bersejarah yang bercampur dengan hunian penduduk, aktivitas pada kawasan pecinan selalu padat dari pagi hingga sore hari.

Pada station 1 gang gambiran Vegetasi yang tersedia meliputi tanaman hias dan peneduh yang mengikuti jaringan jalan. Bangunan yang beriorientasi menghadap timurbarat ini memiliki material bangunan berupa beton dan material penutup lahan berupa aspal. Jika ditinjau dari lebar dan ketinggian bangunan kawasan ini menghasilkan nilai $\mathrm{H} / \mathrm{W}$ 
(geometri) sebesar 3 (Gambar 1) . Pada titik ini, suhu tertinggi berada pada pukul $12.30 \mathrm{WIB}$ ketika matahari berada di atas kepala (tegak lurus). Sebagai salah satu area hunian, aktivitas pada pagi dan siang menjadi lebih minim dibandingkan aktivitas pada sore hari. Hal tersebut kemudian mempengaruhi kualitas udara kawasan, dimana pada sore hari (pukul 16.00 WIB) kualitas udara akan semakin menurun.
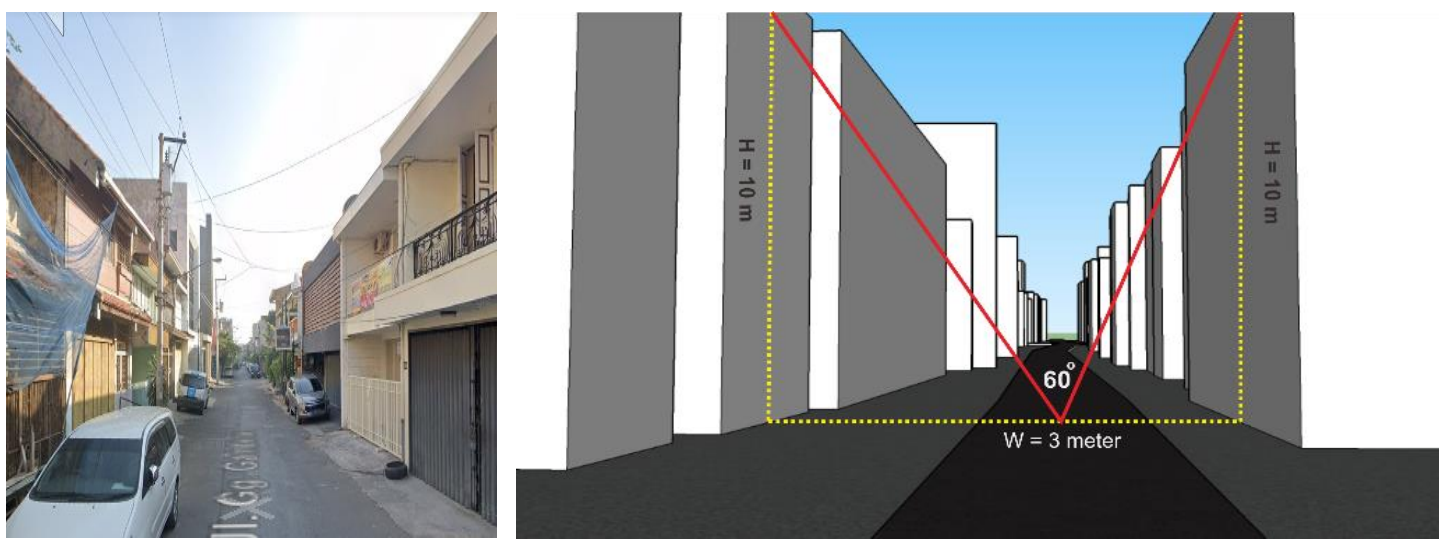

Gambar 1. Geometri Jalan Gang Gambiran Terhadap Bangunan

Bagian station 2 yang berlokasi di Gang Warung merupakan kawasan dengan penggunaan bangunan didominasi oleh perdagangan dan jasa. Dimana kawasan ini menjadi salah satu kawasan tersibuk dari pagi hingga sore hari. Bangunan pada titik ini memiliki ketinggian rata-rata sebesar 8-10 meter dengan KDB sebesar 100\%. Kawasan ini dilengkapi oleh jalur pejalan kaki yang terletak pada bagian depan ruko. Material tutupan lahan berupa paving dengan material bangunan sebagian besar berupa beton berwarna cerah. Bangunan beriorientasi ke arah utara-selatan dengan posisi yang paling menguntungkan adalah pada bangunan yang menghadap utara karena menghasilkan bayangan dengan rata-rata panjang 10 meter sepanjang hari. Jika ditinjau dari nilai H/W (lihat gambar 2), kawasan ini menghasilkan nilai geometeri sebesar 2 . Sementara suhu udara terendah yaitu pada pukul 16.00 WIB, namun banyaknya aktivitas pada sore hari menyebabkan kualitas udara semakin menurun. Minimnya vegetasi menyebabkan adanya bayangan tidak berpengaruh besar terhadap pembentukan iklim sejuk pada kawasan ini, sehingga suhu udara rata-rata relatif tinggi dari pagi hingga sore hari

Bagian station 3 Gang Pinggir juga menjadi salah satu lokasi dengan aktivitas terpadat pada wilayah Pecinan. Hal tersebut dikarenakan kawasan ini merupakan jalur masuk utama dan dipergunakan sebagai kawasan perdagangan dan jasa. Ketinggian bangunan pada kawasan ini dapat mencapai rata-rata sebesar 10-14 meter dengan KDB $100 \%$. Vegetasi berupa tanaman hias dan pengarah biasanya diletakkan mengikuti jalan atau jalur pejalan kaki yang berada di bagian depan ruko. Orientasi bangunan pada kawasan ini adalah ke arah timur-barat dengan material jalan berupa paving dan material bangunan berupa beton berwarna cerah. Suhu terendah yang dihasilkan pada kawasan ini adalah pada sore hari pukul $16.00 \mathrm{WIB}$ dan pada waktu tersebut bayangan menutupi seluruh bagian jalan. Adapun geometri jalan terhadap bangunan yang dihasilkan pada titik ini adalah sebesar 3 (lihat gambar 3). 


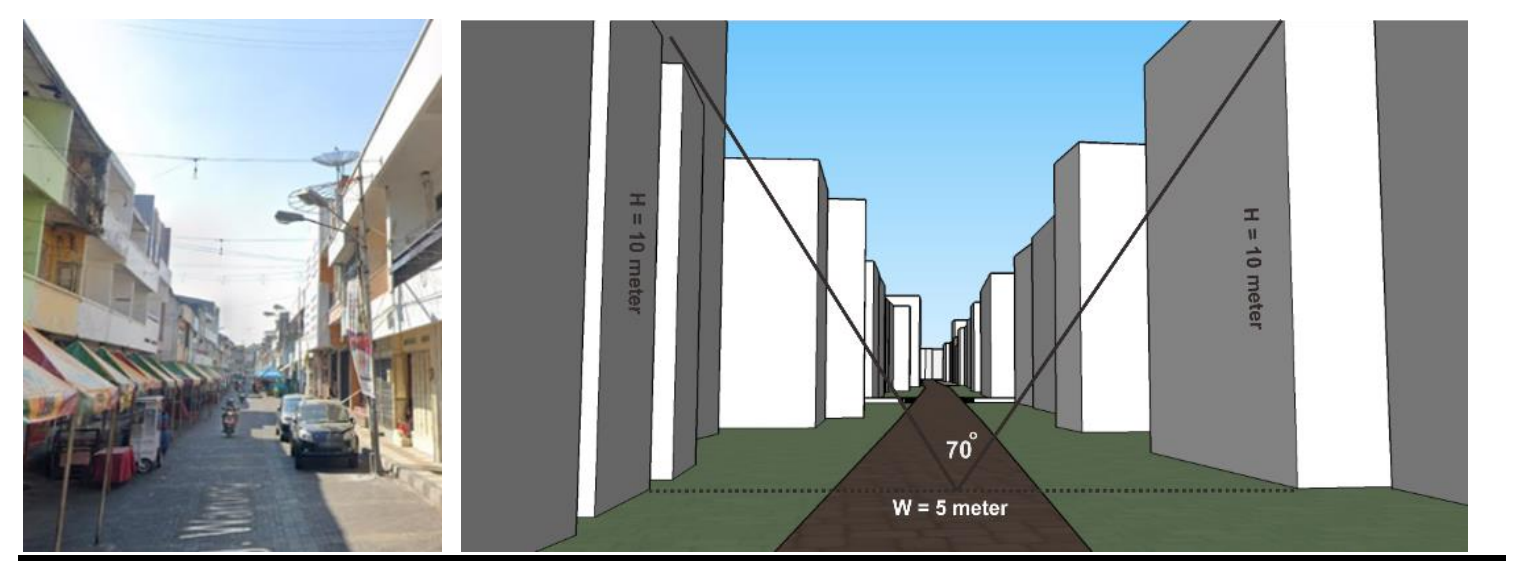

Gambar 2 Geometri Jalan Gang Warung Terhadap Bangunan

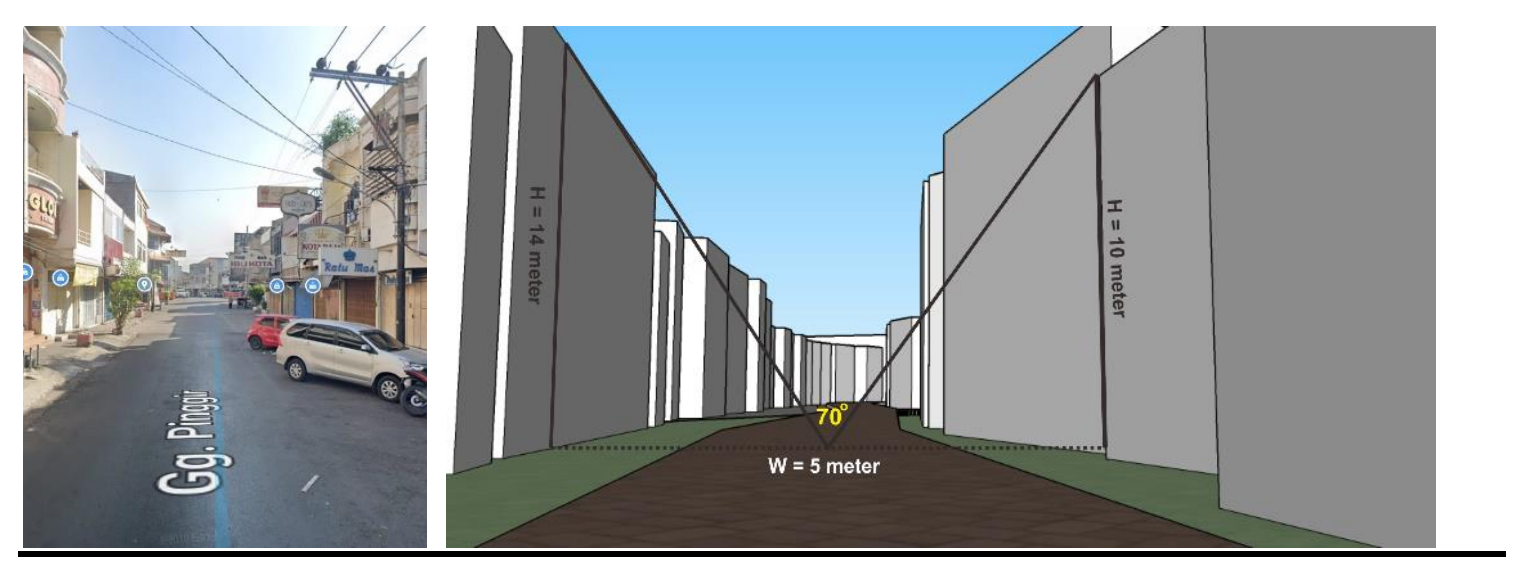

Gambar 3 Geometri Jalan Gang Pinggir Terhadap Bangunan

Hasil simulasi kenyamanan termal, angin, dan bangunan memperlihatkan bahwa pada Kawasan Pecinan pola pergerakan angin disetiap jamnya berbeda-beda. Dimana pergerakan angin yang dihasilkan pada kawasan ini lebih stabil karena pola peletakan bangunan yang stabil dan cenderung berbentuk grid. Dominasi bangunan ruko dengan fasad berbentuk persegi dengan jalan lurus akan menimbulkan aliran udara yang lebih stabil ke dalam maupun ke luar kawasan (Shishegar, 2013). Kenyamanan termal rata-rata Kawasan Pecinan menunjukkan kondisi Tidak Nyaman dengan tingkat kenyamanan termal lebih besar dari angka $27^{\circ} \mathrm{C}$. Bagian utara kawasan yang mencakup Station 2 Gang Warung dan Station 3 Gang Pinggir merupakan kawasan terpanas dengan tingkat kenyamanan termal mencapai $34^{\circ} \mathrm{C}$. Geometri jalan terhadap bangunan (H/W) juga mempengaruhi pembentukan temperatur udara dan aliran angin (Dursun \& Yavas, 2015), dimana pada lokasi Gang Warung dan Gang Pinggir merupakan kawasan yang memiliki geometri yang besar sehingga pembayangan benda akan jauh lebih kecil mengisi lorong jalan.

Berdasarkan hasil olah Ecotect Analysis yang telah dilakukan menunjukan pada pagi hari pukul 09.30 WIB rata-rata bayangan yang dapat dihasilkan pada titik pengambilan sampel adalah sebesar $18 \%$ dengan posisi matahari 30 derajat dari arah timur. Sementara pada siang hari pukul $12.30 \mathrm{WIB}$ saat posisi matahari tegak lurus $\left(80^{\circ}\right)$, rata-rata kawasan menghasilkan bayangan terkecil sebanyak $2 \%$ atau tidak menghasilkan bayangan ( $0 \%)$. Pada waktu sore hari pukul 16.00 WIB dapat menghasilkan bayangan terbanyak hingga mencapai rata-rata bayangan sebesar $55 \%$. 


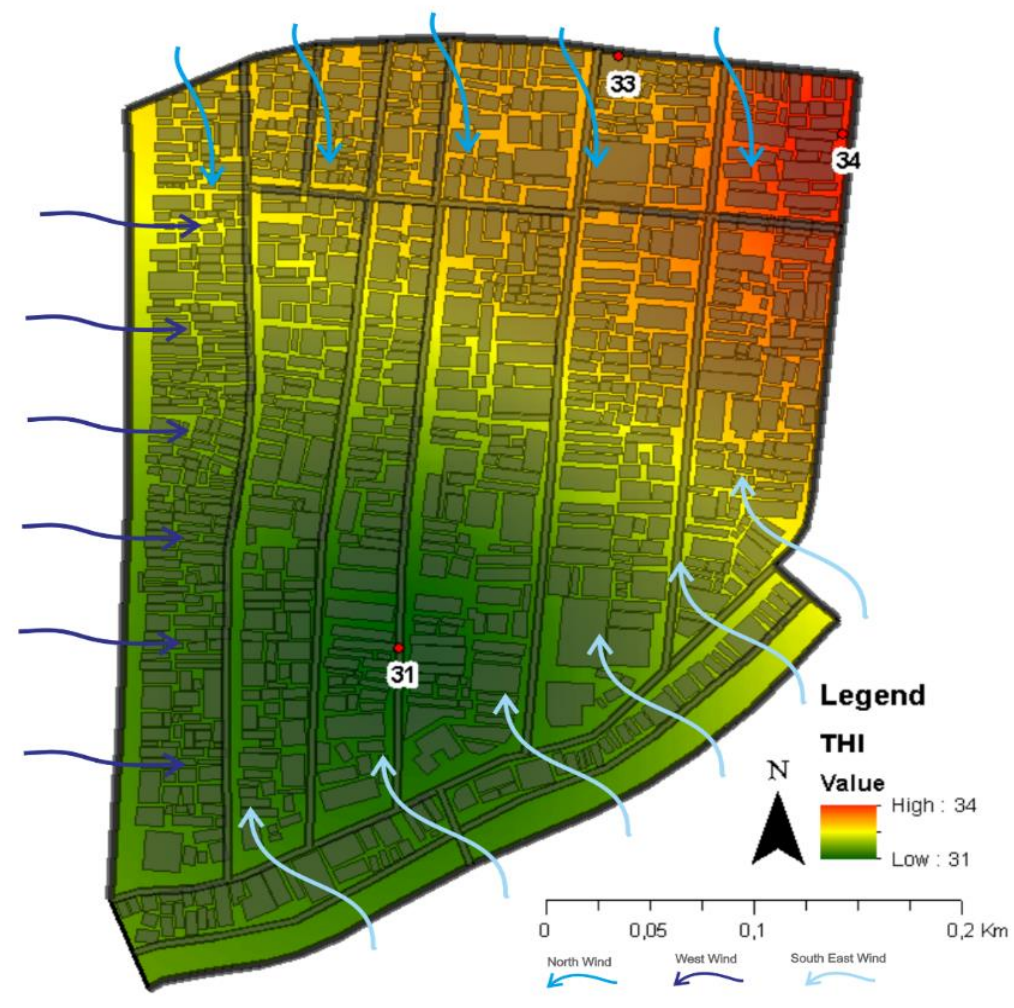

Gambar 4 Simulasi Nilai THI dan Arah Angin terhadap Bangunan di Pecinan

Hal tersebut relevan dengan teori yang disampaikan oleh Bourbia \& Awbi, (2004) bahwa rata-rata bayangan terbesar dihasilkan pada waktu pagi hari hingga menjelang siang dan waktu siang sampai sore hari (menjelang terbenamnya matahari). Pada siang hari persentase bayangan yang dihasilkan sedikit atau tidak ada bayangan sama sekali dikarenakan posisi matahari tepat berada di atas pengamat tegak lurus terhadap permukaan bumi. Selain itu, faktor kenampakan langit (SVF) juga mempengaruhi pembentukan suhu permukaan, dimana semakin tinggi SVF nya akan semakin panas cuaca yang dihasilkan. Hal tersebut berlaku pada Kawasan Pecinan, SVF terbesar berada pada pukul 12.30 WIB (52\%) dimana selama waktu tersebut dihasilkan suhu maksimum berdasarkan hasil perhitungan kenyamanan termal.

\section{Penerapan Konsep CSUD pada Kawasan Pecinan}

Material dan frekuensi lalu lintas menjadi elemen urban design yang berpengaruh langsung terhadap pembentukan iklim mikro yang ada di Kawasan Pecinan. Menurut Johansson (2006) material dari komponen tutupan lahan mempengaruhi nilai refleksi dan penyerapan sinar matahari. Material yang ada di Kawasan Pecinan didominasi oleh paving dan aspal untuk jalan dan beton berwarna cerah pada bangunan. Selain itu, tutupan lahan di kawasan ini sangat minim dikarenakan bangunan tidak memiliki jarak dan cenderung padat. Material jalan yang terbuat dari paving dan aspal, sedangkan bangunannya menggunakan warna cerah. Semua bahan ini membentuk iklim yang panas dan menyerap sedikit panas di pagi dan siang hari.

Sebagai salah satu kawasan perdagangan dan jasa serta permukiman, menyebabkan Kawasan Pecinan padat lalu lintas sepanjang hari. Emisi lalu lintas memiliki pengaruh yang signifikan terhadap kenyamanan termal luar ruangan karena pengaruh polusi udara ( $\mathrm{Li}$, Zhang, Wen, Yang, \& Juan, 2020). 
Selain itu, pembayangan yang terbentuk dari bangunan sangat mempengaruhi pengurangan suhu panas pada pagi dan sore hari. Menurut Bourbia \& Awbi (2004) posisi matahari berubah pada waktu-waktu tertentu, sehingga arah bangunan berpengaruh pada bayangan di permukaan bawah. Sementara orientasi bangunan tidak terlalu berpengaruh pada kawasan ini dikarenakan kepadatan bangunan yang tinggi.

Vegetasi merupakan elemen tambahan yang direkomendasikan ada untuk setiap kawasan untuk meminimalisir peningkatan suhu panas. Suhu vegetasi pada siang hari di atas permukaan tanah terbuka akan lebih tinggi daripada suhu di bawah naungan karena radiasi matahari yang diterima tanaman tidak dapat dipantulkan kembali (Lakitan, 2004). Pemilihan rekomendasi penyesuaian iklim terhadap urban design sebagai berikut:

Tabel 3 Pemilihan Rekomendasi Penyesuaian

\begin{tabular}{|c|c|c|c|}
\hline Kategori & Rekomendasi & Lingkungan & Adaptasi \\
\hline $\begin{array}{l}\text { Material } \\
\text { Bangunan dan }\end{array}$ & Mengubah material bangunan dan jalan. & $\mathrm{B}$ & I \\
\hline Tutupan Lahan & Melakukan pengecetan ulang bangunan. & B & I \\
\hline $\begin{array}{l}\text { Frekuensi Lalu } \\
\text { Lintas }\end{array}$ & $\begin{array}{l}\text { Mengadakan sistem jalur non-motorize pada jalur } \\
\text { utama kawasan }\end{array}$ & $\mathrm{T}$ & B \\
\hline \multirow[t]{3}{*}{ (Aktivitas) } & $\begin{array}{l}\text { Mengalihkan arus kendaraan pada jam-jam sibuk } \\
\text { wisata }\end{array}$ & $\mathrm{I}$ & B \\
\hline & $\begin{array}{l}\text { Optimalisasi penggunaan moda angkutan umum } \\
\text { Trans Semarang }\end{array}$ & B & B \\
\hline & $\begin{array}{l}\text { Optimalisasi kantung-kantung parkir } \\
\text { Optimalisasi pengadaan becak wisata }\end{array}$ & $\mathrm{T}$ & B \\
\hline \multirow[t]{6}{*}{ Vegetasi } & Penambahan RTH Aktif dan pasif & B & I \\
\hline & Penanaman pohon sepanjang koridor & B & $\mathrm{T}$ \\
\hline & Optimalisasi tanaman dalam pot & B & B \\
\hline & Penggunaan pergola sepanjang koridor & B & $\mathrm{S}$ \\
\hline & Tanaman gantung setiap bangunan & B & B \\
\hline & $\begin{array}{l}\text { Penambahan vegetasi merambat pada dinding } \\
\text { bangunan. }\end{array}$ & B & B \\
\hline
\end{tabular}

Pengaturan lalu lintas dan aktivitas seperti pemaksimalan angkutan umum Bus Trans Semarang direkomendasikan untuk meminimalisir polusi udara dan meningkatkan koneksi antar kawasan di Kota Lama. Jumlah penggunaan kendaraan bermotor yang tinggi berpengaruh pada emisi $\mathrm{CO}_{2}$ yang dikeluarkan sehingga akan mempengaruhi suhu kawasan. Selain itu, kendaraan bermotor juga memberikan polusi suara yang sangat mengganggu sehingga akan mempengaruhi tingkat kenyamanan (Andriani \& Yuliastuti, 2013). Pengaturan lalu lintas dengan pembatasan jumlah kendaraan bermotor dapat meningkatkan kualitas udara di daerah perkotaan (Gusnita, 2010). Sehingga solusi mengurangi penggunaan kendaraan bermotor pada Kawasan Pecinan yaitu dengan memaksimalkan penggunaan angkutan umum.

Dalam upaya menciptakan iklim mikro yang nyaman, penataan dan penempatan vegetasi harus diperhatikan (Boutet, 1987). Kawasan Pecinan merupakan salah satu kawasan cagar budaya yang dilindungi di Kota Semarang sehingga dibutuhkan rekomendasi yang seminimal mungkin merusak struktur alami kawasan. Rekomendasi untuk kawasan pecinan adalah dengan adaptasi atau revitalisasi kawasan. Dalam Charter (1999) adaptasi atau revitalisasi merupakan proses mengubah suatu tempat agar dapat digunakan untuk fungsi yang sesuai dengan kegunaannya dengan melakukan proses perubahan dengan dampak seminimal mungkin. Gambar 6 dibawah ini menunjukkan titik yang disarankan untuk diterapkan penambahan vegetasi pada kawasan pecinan. 


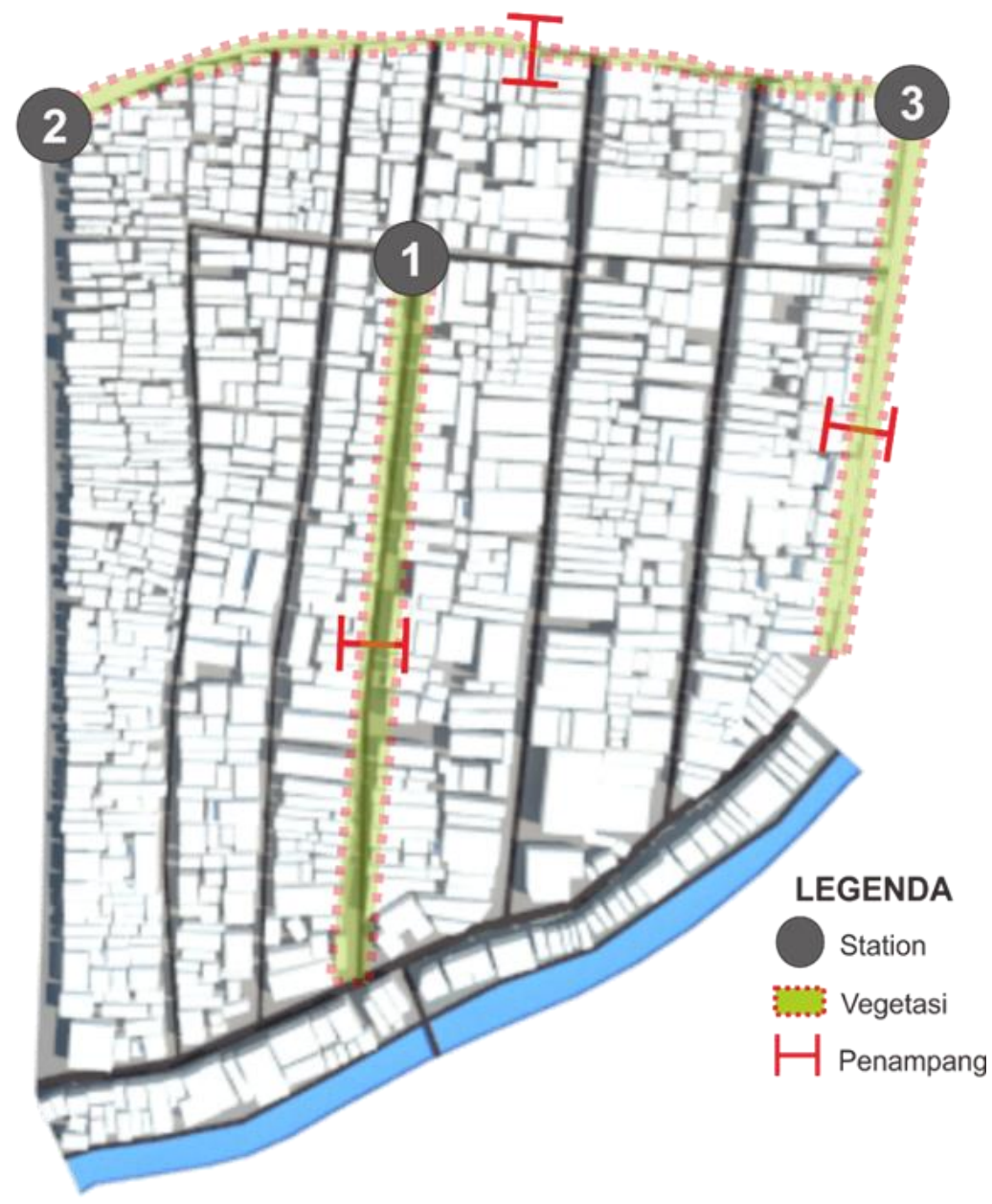

Gambar 6 Titik Rekomendasi Desain Kawasan Pecinan

Kawasan pecinan didominasi dengan bangunan hunian dan tidak banyak terdapat ruang untuk dilakukan penanaman pohon. Pada kondisi padat bangunan terdapat beberapa upaya menanam vegetasi diantaranya penggunaan pot dan vertical garden. Penggunaan pot dapat meminimalisir konsumsi yang besar sehingga model yang disarankan yaitu dengan hidroponik (Chandra \& Fatimah, 2019). Pemilihan bentuk hydroponic yang lebih ramping dan mudah dimodifikasi sangat cocok untuk kawasan pecinan dengan aktivitas permukiman yang lebih besar sepanjang hari. Menurut Hendrawati (2016), pengadaan pipa-pipa yang dapat dialiri air akan menciptakan iklim sejuk pada kawasan sekitarnya. Sehingga pengadaan tanaman vertikal jenis hydroponic cocok digunakan untuk menyimpan air sekaligus pengadaan tanaman hijau pada kawasan. Sementara itu, vertical garden dapat dilakukan dengan penghijauan pada fasade bangunan sehingga menggunakan tanaman merambat dan menggantung (Ferial, 2007). Berikut dibawah ini bentuk penempatan vegetasi yang direncanakan pada kawasan pecinan kota semarang lihat gambar 7 . 

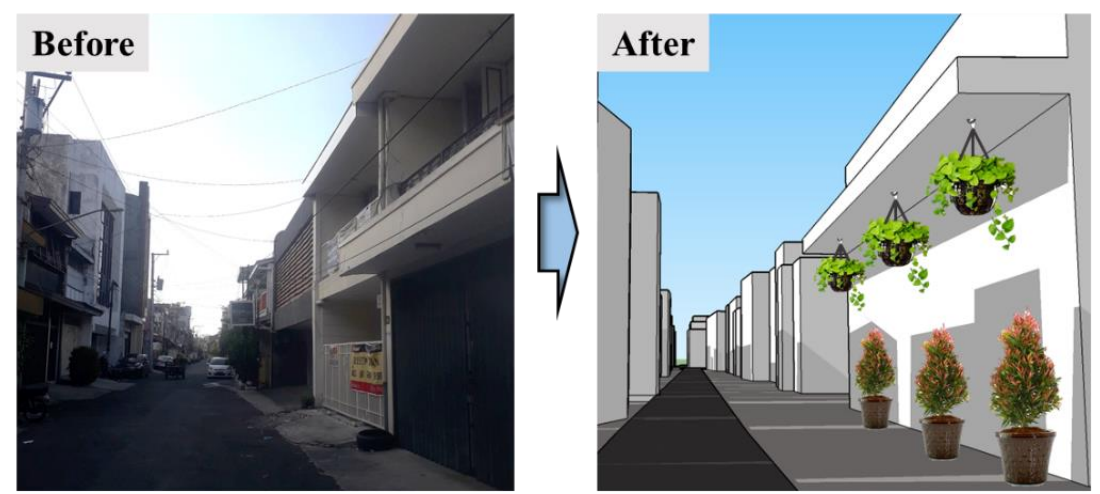

a) Rekomendasi Desain Station 1
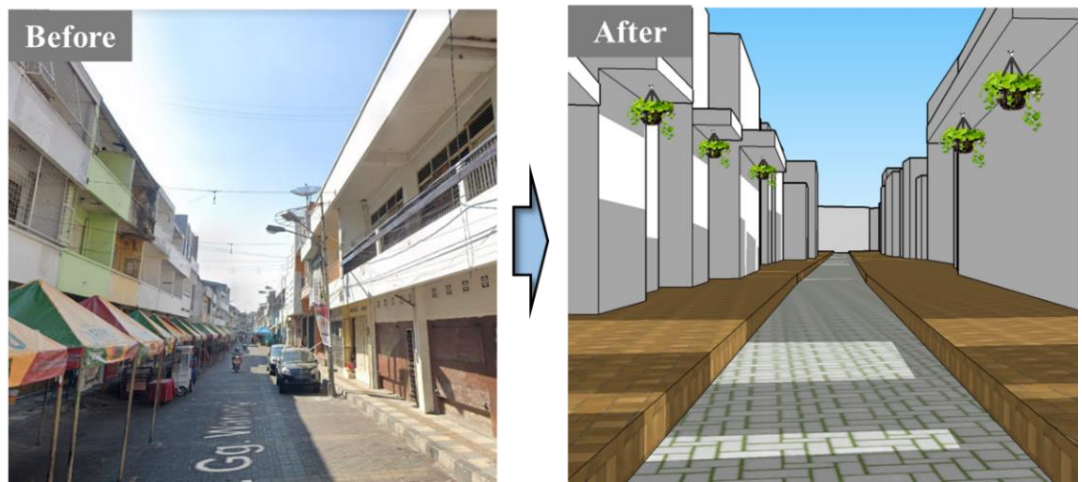

b) Rekomendasi Desain Station 2
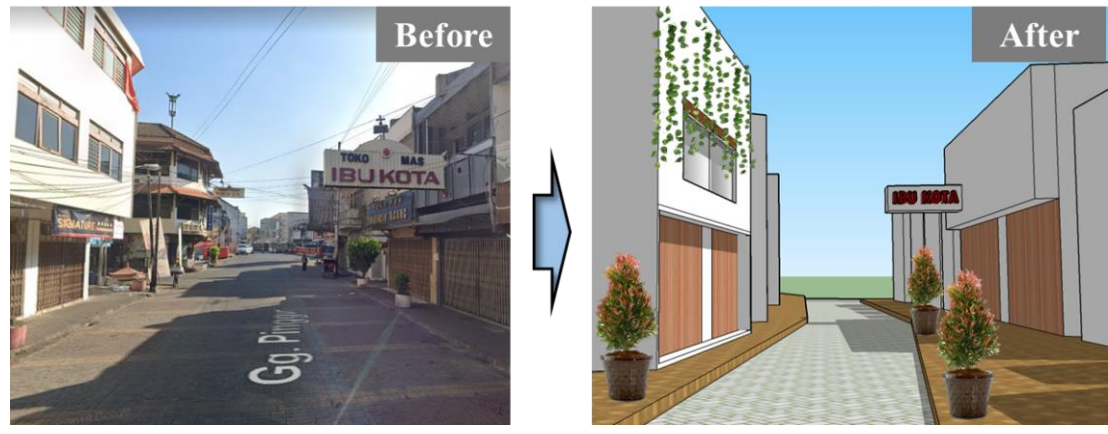

c) Rekomendasi Desain Station 3
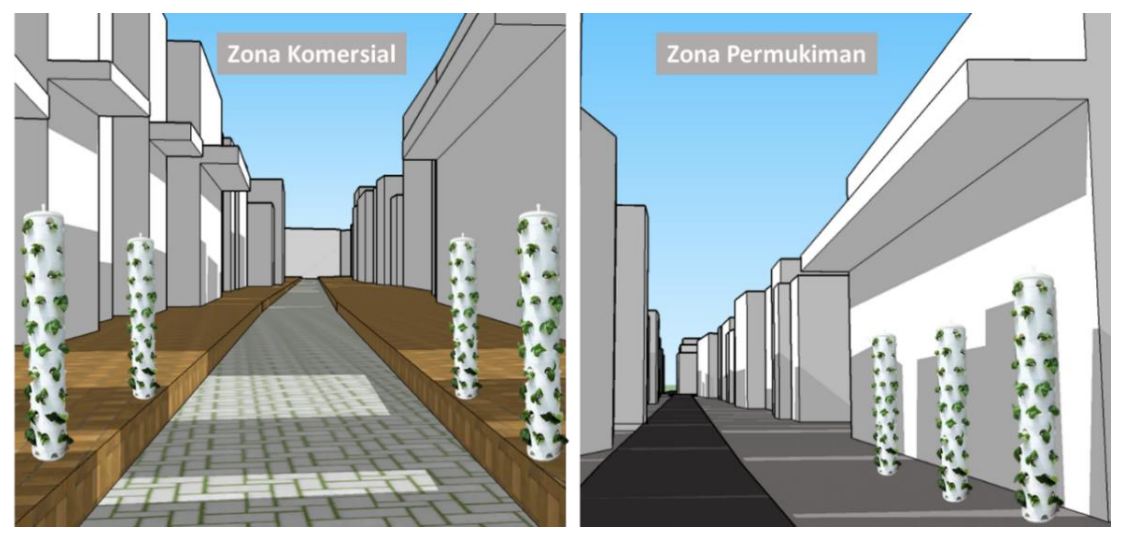

d) Rekomendasi Vertical Hydroponic System

Sumber: Survey Primer dan Olah Data Peneliti, 2020

\section{Gambar 7 Sampel Desain Rekomendasi Penyesuaian Iklim Pecinan}




\section{KESIMPULAN}

Suhu kawasan pecinan yang terasa lebih panas dibandingkan area sekitarnya lebih dipengaruhi oleh aktivitas lingkungan atau frekuensi lalu lintas dan minimnya vegetasi. Meskipun keberadaan bangunan yang cukup padat pada kawasan pecinan dapat menjadi pembayangan kawasan namun kenyamanan masih berada pada tingkat tidak nyaman. Oleh karena itu rekomendasi arahan pengelolaan lingkungan kawasan pecinan Kota Semarang dapat dilakukan dengan mengoptimalisasikan penggunaan moda angkutan umum menuju kawasan, optimalisasi pengadaan vegetasi berupa tanaman dalam pot, tanaman gantung pada kanopi bangunan, dan vegetasi yang merambat pada dinding bangunan. Optimalisasi penggunaan moda angkutan umum ditujukan pada pemerintah kota semarang untuk membuat kebijakan penggunaan angkutan umum pada kawasan pecinan. Sementara itu untuk optimalisasi vegetasi, pada station 1 diarahkan penambahan vegetasi dengan tanaman pot dan tanaman gantung. Untuk station 2 menggunakan jenis tanaman gantung saja karena pada koridor jalan ini banyak terdapat stand untuk PKL. Pada station 3 menambahkan tanaman dengan pot dan tanaman merambat pada dinding bangunan.

\section{PERNYATAAN RESMI}

Terima kasih kepada Direktorat Riset dan Pengabdian Masyarakat, Deputi Bidang Penguatan Riset dan Pengembangan, Kementrian Riset dan Teknologi/ Badan Riset dan Inovasi Nasional yang telah membiayai penelitian dasar unggulan perguruan tinggi ini melalui Sumber Dana DRPM Kemenristek Dikti Tahun Anggaran 2020.

\section{DAFTAR PUSTAKA}

Andriani, D. M., \& Yuliastuti, N. (2013). Penilaian Sistem Transportasi yang Mengarah Pada Green Transportasi di Kota Surakarta. Jurnal Pembangunan Wilayah \& Kota, 9(2), 183. https://doi.org/10.14710/pwk.v9i2.6535

Bourbia, F., \& Awbi, H. B. (2004). Building Cluster and Shading in Urban Canyon for Hot Dry Climate Part 2: Shading Simulations. Renewable Energy, 29(2), 291-301. https://doi.org/10.1016/S0960-1481(03)00171$\mathrm{X}$

Boutet, T. S. (1987). Controlling Air Movement : A Manual for Architects and Builder. McGraw-Hill New York.

Chandra, B., \& Fatimah, T. (2019). Pemanfaatan Keterbatasan Lahan untuk Ruang Terbuka Hijau di Kampung Luar Batang. Seminar Nasional Pembangunan Wilayah dan Kota Berkelanjutan, (September), 5-12. https://doi.org/10.25105/pwkb.v1i1.5254

Charter, B. (1999). The Australia ICOMOS Charter for Places of Cultural Significance.

Djukic, A., Vukmirovic, M., \& Stankovic, S. (2016). Principles of Climate Sensitive Urban Design Analysis in Identification of Suitable Urban Design Proposals. Case study: Central zone of Leskovac competition. Energy and Buildings, (115), 23-35.

Dursun, D., \& Yavas, M. (2015). Climate-Sensitive Urban Design in Cold Climate Zone: The city of Erzurum, Turkey. International Review for Spatial Planning and Sustainable Development, 3(1), 17-38. https://doi.org/10.14246/irspsd.3.1_17

Emmanuel, M. R. (2005). An Urban Approach to Climate-Sensitive Design. New York: Spon Press.

Ferial, R. (2007). Bangunan Tinggi dan Lingkungan Kota. TeknikA, 1(28), 92-97.

Giannopoulou, K., Livada, I., Santamouris, M., Saliari, M., Assimakopoulos, M., \& Caouris, Y. G. (2011). On the Characteristics of the Summer Urban Heat Island in Athens, Greece. Sustainable Cities and Society, 1(1), 16-28. https://doi.org/10.1016/j.scs.2010.08.003

Gusnita, D. (2010). Green Transport : Transportasi Ramah Lingkungan Dan Kontribusinya Dalam Mengurangi Polusi Udara. Berita Dirgantara, 11(2), 66-71.

Hendrawati, D. (2016). Air Sebagai Alat Pengendali Iklim Mikro Dalam Bangunan Studi Kasus : Taman Sari Royal Heritage Spa, Hotel Sheraton Mustika Yogyakarta. Jurnal Teknik Sipil dan Perencanaan, 18(2), 97106. https://doi.org/10.15294/jtsp.v18i2.7477

Johansson, E. (2006). Influence of urban geometry on outdoor thermal comfort in a hot dry climate : A study in $\mathrm{Fez}$ Morocco. Building and Environment, 41, 1326-1338. https://doi.org/10.1016/j.buildenv.2005.05.022 
Kaya, N., \& Mengi, O. (2011). How Sensitive We Build to Climate? Design for Comfortable Urban Environment. 47th ISOCARP Congress.

Koch-Nielsen, H. (2002). Stay Cool: A Design Guide for the Built Environment in Hot Climates (1st Editio). https://doi.org/10.4324/9781315074429

Koerniawan, M. D. (2015). The Simulation Study of Thermal Comfort in Urban Open Spaces of Commercial Area Using EnviMet Software. AIJ Japan. Tokyo.

Kolokotroni, M., \& Giridharan, R. (2008). Urban Heat Island Intensity in London: An Investigation of the Impact of Physical Characteristics on Changes in Outdoor Air Temperature During Summer. Solar Energy, 82(11), 986-998. https://doi.org/986-998. 10.1016/j.solener.2008.05.004.

Laurie, M. (1990). Pengantar kepada Arsitektur Pertamanan. Bandung: Bandung Intermatra.

Nichol, J. E., Fung, W. Y., Lam, K., \& Wong, M. S. (2009). Urban heat island diagnosis using ASTER satellite images and ' in situ ' air temperature. Atmospheric Research, 94, 276-284. https://doi.org/10.1016/j.atmosres.2009.06.011

Pamungkas, B. A., Munibah, K., \& Soma, S. (2019). Land Use Changes and Relation to Urban Heat Island (case study: Semarang City, Central Java. IOP Conference Series: Earth and Environmental Science. Bogor: IOP Publishing.

Pemerintah Kota Semarang. (2011). Rencana Tata Ruang Wilayah Kota Semarang tahun 2011-2031. Semarang.

Pramono, G. H. (2008). Akurasi Metode IDW dan Kriging untuk Interpolasi Sebaran Sedimen Tersuspensi. Forum Geografi, 22(1), 97-110.

Rachma, L. (2018). Evaluasi Kenyamanan Termal dan Kecukupan Ruang Terbuka Hijau di Kawasan Industri PT Krakatau Steel, Kota Cilegon. Institut Pertanian Bogor.

Shishegar, N. (2013). Street Design and Urban Microclimate: Analyzing the Effects of Street Geometry and Orientation on Airflowand Solar Access in Urban Canyons. Journal of Clean Energy Technologies, 1(1), 5256. https://doi.org/10.7763/jocet.2013.v1.13

Tapias, E., \& Schmitt, G. (2014). Climate-Sensitive Urban Growth : Outdoor Thermal Comfort as an Indicator for the Design of Urban Spaces. WIT Transactions on Ecology and the Environment, (191). https://doi.org/10.2495/SC140521

Widiastuti, R. (2015). Conservation an Effort to Protect the Identity of the Historical Environment (Case Study Historical Environment Semarang Chinatown). Jurnal PKKM III, 241-246.

Wismonowati, D. (2012). Kajian Tingkat Kenyamanan Fisik Ruang dalam Berdasarkan Persepsi Pengguna. Universitas Negeri Semarang. 